
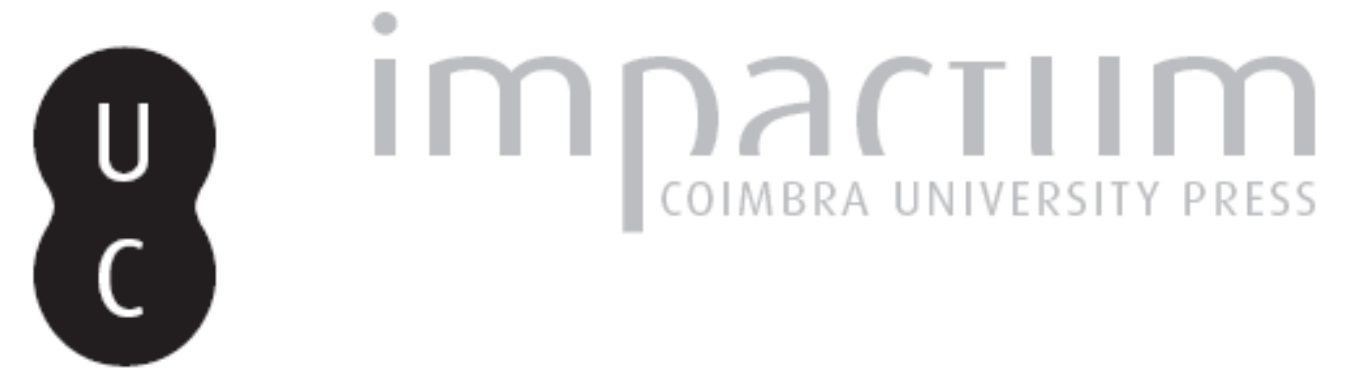

"Das casas da inuocação de Loreto que ha em Portugal"

Autor(es): $\quad$ Mendes, Rui Manuel Mesquita

Publicado por: Imprensa da Universidade de Coimbra

URL persistente:

URI:http://hdl.handle.net/10316.2/45637

DOI:

DOI:https://doi.org/10.14195/0870-8584_13_4

Accessed : $\quad$ 26-Apr-2023 12:36:45

A navegação consulta e descarregamento dos títulos inseridos nas Bibliotecas Digitais UC Digitalis, UC Pombalina e UC Impactum, pressupõem a aceitação plena e sem reservas dos Termos e Condições de Uso destas Bibliotecas Digitais, disponíveis em https://digitalis.uc.pt/pt-pt/termos.

Conforme exposto nos referidos Termos e Condições de Uso, o descarregamento de títulos de acesso restrito requer uma licença válida de autorização devendo o utilizador aceder ao(s) documento(s) a partir de um endereço de IP da instituição detentora da supramencionada licença.

Ao utilizador é apenas permitido o descarregamento para uso pessoal, pelo que o emprego do(s) título(s) descarregado(s) para outro fim, designadamente comercial, carece de autorização do respetivo autor ou editor da obra.

Na medida em que todas as obras da UC Digitalis se encontram protegidas pelo Código do Direito de Autor e Direitos Conexos e demais legislação aplicável, toda a cópia, parcial ou total, deste documento, nos casos em que é legalmente admitida, deverá conter ou fazer-se acompanhar por este aviso. 


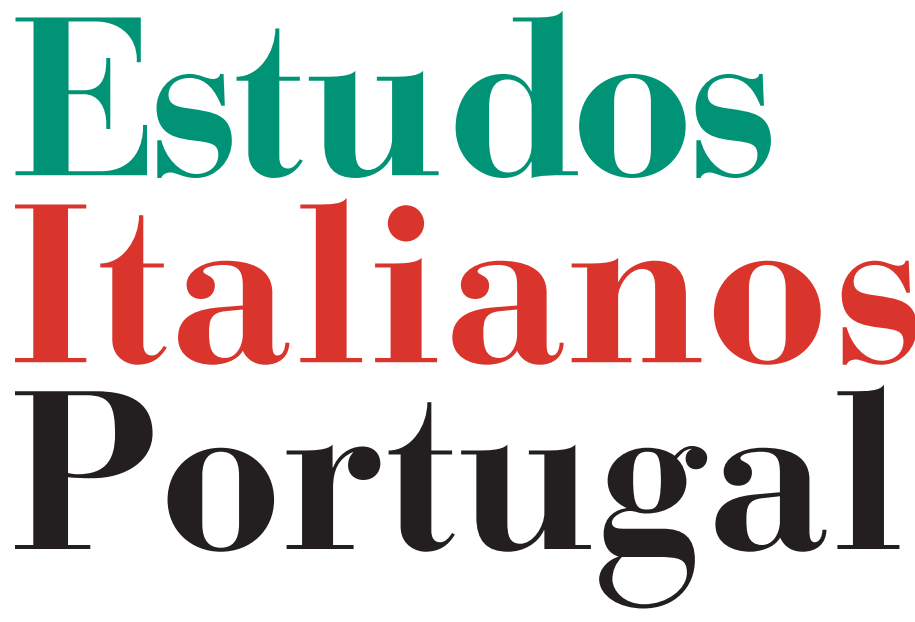

Instituto

Italiano

de Cultura

de Lisboa

Nova Série

$\mathrm{N}^{\mathbf{0}} 13$

2018 


\title{
"DAS CASAS DA INUOCAÇÃO DE LORETO QUE HA EM PORTUGAL"1
}

\author{
Rui Manuel Mesquita Mendes*
}

Andam escriptas narrações tão pouco verosímeis, que ainda que caibam no possível, manda a prudência que se não acreditem sem analyse.

Abade de Castro, $1848^{2}$

\section{INTRODUÇĀO}

QuANDo em 1715 D. João V, rei de Portugal, se preparava para conhecer a Europa, viajando por Itália, Alemanha, Holanda, Inglaterra e França, fá-lo em razão de uma "promessa de ir em romaria a NS do Loreto (que) estava determinado a cumpril a com a maior brevidade, indo por terra (...) tencionava partir em 4 d'Outubro para se achar no Loreto pelo Natal" (Santarém 1845: 152-153); uma viagem que nunca chegará a fazer, mas cujo propósito mostra como, ainda no século XVIII, esta era uma casa de romagem com grande devoção em Portugal.

De facto, apesar da tradição do Milagre da trasladação da Santa Casa da Virgem da Nazaré para a Dalmácia (1291) e depois para Loreto na região das Marcas (1294) ser antiga, o seu culto só conheceu uma verdadeira expansão a partir da segunda metade do século XV e sobretudo a partir da construção do templete que envolve a "Santa Casa", segundo o projecto de Donato Bramante (1509) e debaixo da direcção

* Licenciado em História pela Faculdade de Letras da Universidade de Lisboa e em Engenharia Industrial pela Universidade Nova de Lisboa. Investigador independente e colaborador do ARTIS - Instituto de História da Arte da FLUL maildoruimendes@ gmail.com

${ }^{1}$ Brandão 1650: 200.

${ }^{2}$ Castro 1848: 499. 
de Andrea da Sansovino (1513-1527) ${ }^{3}$, escultor e arquitecto que anos antes estivera em Portugal. Na realidade, já nessa época eram comuns em Portugal e demais cristandade "os votos de ir a Roma ou a Hierusalem ou a Sanctiago ou a Nossa Senhora do Loreto ou voto de religiam e castidade", como se refere na Bula da Cruzada concedida a Portugal em $1528^{4}$.

Deste modo, fica claro que, quando em 1518 se constituiu em Lisboa a capela dos mercadores italianos sob a protecção da Virgem do Santuário do Loreto, este era já um dos mais famosos lugares de peregrinação em Itália e da Europa, não sendo por isso de admirar que portugueses que demandassem aquelas paragens de lá trouxessem ecos de uma devoção muito própria e sobejamente conhecida.

Contudo, a introdução do culto de Nossa Senhora do Loreto em Portugal não é, como se poderia pensar, uma novidade trazida apenas e exclusivamente pelos importantes mercadores italianos do período joanino e manuelino, mas já cá se achavam ecos da Virgem do Loreto, nomeadamente pela mão de D. Fernando Coutinho, Bispo do Algarve (1501-1538), que em Lagos fundara uma casa "por enuocaçam nossa Senhora de Loreto, por quanto em huma graussima doemça que tiuemos, em sendo escolar em Frorença, lhe emcomendamos a nossa alma, \& saude á dicta Senhora, \& polla misericordia de nosso Senhor, \& ssua interçessam rrecebimos saude, $\&$ temos particular deuoçam aa dicta Cassa; \& a custumavamos da vissitar cada anno em quanto em as dictas terras estiuemos, \& em nossos diuinos ofiçios fazemos della particular comemoraçam" 5 .

${ }^{3}$ http://www.santuarioloreto.it/internal_standard.asp?body=as0 1 \&sezione=as (2.6.2018).

${ }^{4}$ Arquivo Nacional Torre do Tombo, Lisboa (ANTT)., Gavetas, IV, XV, 10-12, doc. 3245.

5 ANTT., Leitura Nova, Odiana, liv. 7, fl. 105v-107v, na povoação de Silves o Novo, 21-7-1520; Évora, 6-8-1520; Brandão, 1650: 201. 
Investigámos a cronologia e diversidade de lugares de culto dedicados a Nossa Senhora do Loreto em Portugal, fazendo a recolha bibliográfica possível, atendendo aos breves estudos dedicados ao tema ${ }^{6}$. Contudo, é já longa a bibliografia dedicada ao estudo da mariologia ${ }^{7}$, a que recorremos, bem como aos dicionários geográficos (Corographia Portugueza 1706-1712; Cardoso, 1747-1751) e memórias paroquiais já publicadas, nomeadamente pela equipa do professor José Viriato Capela.

Procurámos assim identificar as paróquias, conventos, capelas públicas e privadas, e alguns dos altares ou imagens da Senhora do Loreto que se erigiram em Portugal, continental e insular, bem como as circunstâncias da sua fundação.

\section{PARÓQUias (4)}

Segundo o Anuário Católico, existem actualmente em Portugal três paróquias dedicadas a Nossa Senhora do Loreto Juromenha, Paradela do Vouga e Lombada do Loreto - a que

${ }^{6} \mathrm{Na}$ realidade demos conta apenas de um verbete (Pinho Leal - "Senhora do Loreto", Portugal antigo e moderno : diccionario geographico, IX, 1880, pp. 140-142) e um artigo de A. Franquelim S. Neiva Soares - "Capelas de Nossa Senhora do Loreto na Arquidiocese de Braga”, Cadernos do Noroeste, 8:2 1995, pp. 5-46.

${ }^{7}$ Esta teve um grande impulso inicial na famosa obra do Pe. Frei Agostinho de Santa Maria, o "Santuário Mariano" (1707-1722), a que se sucederam as obras de Alberto Pimentel, História do culto de Nossa Senhora em Portugal, 1890; Pe. José Quelhas Bigotte, O culto de Nossa Senhora na Diocese da Guarda, 1900 e 1948; J. G. de Oliveira Guimarães, Guimarães e Santa Maria: Historia do culto de Nossa Senhora no Concelho de Guimarães, 1904; António José Moita, O culto de Maria no Patriarcado: memória do Patriarcado de Lisboa ao Congresso Mariano reunido em Braga, em Maio de 1926; Cónego Manuel de Aguiar Barreiros, Nossa Senhora nas suas imagens e no seu culto na Arquidiocese de Braga, 1931; António Mourinho, Santa Maria e a nossa terra: para a história do culto de Nossa Senhora em Portugal, 1946; Luís Chaves, O culto mariano em Lisboa, 1961; Pe. Henrique da Silva Louro, O culto de nossa Senhora e dos Santos na arquidiocese de Évora, 1967; Carlos Alberto Ferreira de Almeida, O culto da Nossa Senhora, no Porto, na época moderna, 1979; Pe. José do Vale Carvalheira, Nossa Senhora na história e devoção do povo português, ed. Salesianas, 1988; João Martins Vieira, Invocaçōes a Nossa Senhora na cidade de Lisboa, Livros Horizonte, 2017. 
se devem juntar a própria igreja do Loreto em Lisboa, que durante algum tempo também uma das paróquias da cidade.

Destas paróquias, a mais antiga é a da vila de Juromenha (Alandroal), castelo alentejano doado a D. Gonçalo Viegas, mestre da ordem de Avis em $1187^{\circ}$, e cuja igreja (ainda que sem invocação) aparece referida pela primeira vez em $1255^{\circ}$. Em 1396 esta já é referida como Igreja de Santa Maria da Juromenha ${ }^{10}$ e em 1557 como Igreja de Nossa Senhora do Castelo da villa de Juromenha ${ }^{11}$, mas só no início do século XVII é que ali encontramos mencionado o culto do Loreto, por intermédio da aprovação do compromisso da Irmandade de Nossa Senhora do Loreto, orago da Igreja matriz da vila de Juromenha, em 8 de Novembro $1603^{12}$.

Além da igreja de Juromenha, também foi paróquia a já mencionada Igreja do Loreto de Lisboa, cuja história é sobejamente conhecida, fundada por mercadores italianos em 1518 e aberta ao culto em 1522, foi erigida em paróquia da cidade de Lisboa em 1551. Por diferenças com o Cabido da Sé, a paróquia do Loreto foi transferida em 1679 para a Ermida de Nossa Senhora do Alecrim, até que, pela construção da primeira igreja de Nossa Senhora da Encarnação, inaugurada em 1709, esta passou a ser a sede da mesma (Vieira 2017: 103 e 117).

A terceira paróquia dedicada à Virgem do Loreto, à semelhança de Juromenha, também teve origem numa igreja

${ }^{8}$ ANTT, Ordem de Avis e Convento de São Bento de Avis, mç. 2, n. ${ }^{\circ} 65$.

${ }^{9}$ ANTT, Ordem de Avis e Convento de São Bento de Avis, mç. 2, n. ${ }^{\circ} 122$.

${ }^{10}$ ANTT, Ordem de Avis e Convento de São Bento de Avis, mç. 6, n. 598.

${ }^{11}$ ANTT, Mesa da Consciência e Ordens, Chancelaria da Ordem de São Bento de Avis, Chancelaria Antiga, liv. 1, fl. 142v. Carta de apresentação do priorado no Pe. João Gomes, 26.2.1557.

12 ANTT, Mesa da Consciência e Ordens, Chancelaria da Ordem de São Bento de Avis, Chancelaria Antiga, liv. 9, fl. 260-260v; http://www.monumentos.pt/Site/ APP_PagesUser/SIPA.aspx?id=8867 (2.6.2018). Esta igreja foi abandonada no início do século XX e a imagem da padroeira foi transferida para a Ermida de Santo António, que serve actualmente de paroquial (Almeida e Belo, 2008: 246-247). 
mariana mais antiga, trata-se da igreja e paróquia de Paradela (Sever do Vouga), desanexada da freguesia de Pessegueiro por Despacho do Juízo Eclesiástico de Viseu de 30 de Maio de 1740. A nova igreja dedicada a Nossa Senhora do Loreto foi construída no lugar da Capela de Nossa Senhora da Ouvida pelos moradores do lugar e pelo Abade de Pessegueiro, por ordem do visitador dada em 29 de Maio de 1747, sendo esta benzida em 23 de Janeiro de 1750 (Tavares 1989: 71-73). Foi depois profundamente remodelada no século XX, com um projeto modernista do arquitecto Fernando Serra, sendo a nova igreja benzida em 3 de Junho de 1973.

A mais recente paróquia desta invocação foi erigida na Ilha da Madeira, já no século XX, no lugar da Lombada do Loreto, freguesia de Arco da Calheta, em 1961, com sede na ermida quinhentista do mesmo nome, cuja história adiante detalharemos.

\section{Conventos (4)}

É no âmbito das casas conventuais portuguesas que se encontra a maior afinidade entre o culto da Virgem do Loreto em Portugal e a devoção franciscana. De facto, todas as quatro casas a ela dedicadas foram fundações da Ordem de São Francisco, sendo a mais antiga a de Santiago do Cacém, ainda que a sua cronologia careça de dados conclusivos. Fr. Jerónimo de Belém, na sua Chronica serafica de Santa Provincia dos Algarves da Regular (Tomo II 1753: 124-131) dános o relato da fundação da Casa do Loreto em Santiago do Cacém, referindo uma bula concedida ao Venerável Fr. Gomes do Porto, dando-o como ermita e fundador da casa pelos anos de 1454. Contudo, outros autores dizem que a mesma se fundara no ano de 1505 por Dona Maria, mulher de Pedro Pantoja, alcaide-mor da vila (Brandão 1650: 201; Conceição 1740: 42). Será esta última provavelmente a data mais certa, não só por ser mais consentânea com as origens 
do culto da Virgem do Loreto - cuja expansão acontece precisamente nos fins do século XV - como também pelo facto de Pedro Pantoja, conselheiro régio, alcaide-mor e comendador de Santiago do Cacém, ser apenas mencionado na chancelaria de D. Manuel (1495-1521), ainda que aí se diga que a sua mulher se chamava Catarina ${ }^{13}$.

Pelos anos de 1518 foi fundada uma segunda casa franciscana com a invocação do Loreto, por devoção de D. Fernando Coutinho, Bispo do Algarve, que dela fez doação à Província da Piedade em 21 de Julho de 1520, afirmando que "lhe damos a Cassa e mosteiro de lagos, que nos fabricamos com todollos chãos e herdamentos comarcãos que nos compramos pera ella, a quall cassa demos por enuocaçam nossa Senhora de Loreto, por quanto em huma graussima doemça que tiuemos, em sendo escolar em Frorença, lhe emcomendamos a nossa alma, \& saude á dicta Senhora, \& polla misericordia de nosso Senhor, \& ssua interçessam rrecebimos saude, \& temos particular deuoçam aa dicta Cassa; \& a custumavamos da vissitar cada anno em quanto em as dictas terras estiuemos, \& em nossos diuinos ofiçios fazemos della particular comemoraçam" 14 .

As outras duas casas conventuais com a invocação do Loreto são já fundações da segunda metade do século XVI e foram edificadas a norte do rio Tejo, a saber:

- o Recolhimento de Almeida, fundada por umas beatas como recolhimento de irmãs terceiras, pelos anos de 1554, no lugar de Nave, termo de Sabugal (Santa Maria 1711: 219220), mudaram-se estas depois para a vila de Almeida, onde já se achavam em 1587 (Conceição 1740: 145);

- o Convento de Paio de Pele ou Tancos (Vila Nova da Barquinha), fundado por D. Álvaro Coutinho, Sr. do Castelo de Almourol, neto de D. Vasco Coutinho, $1 .^{\circ}$ Conde de

${ }^{13}$ ANTT, Chancelaria de D. Manuel I, liv. 13, fl. 9v, 20.2.1500.

${ }^{14}$ ANTT, Leitura Nova, Odiana, liv. 7, fl. 105v-107v; Brandão, 1650: 201; Cardoso, 1657: 333 . 
Redondo, que lhe deu esta invocação pela grande devoção que tinha a este santuário, e cuja primeira pedra se colocou em 13 de Março de 1572. Fez-se uma nova igreja em 1575 e uma terceira em que se disse a primeira missa em 29 de Julho de 1685 (Santa Maria 1711: 500-507).

\section{Capelas públicas (13)}

Se a Casa do Loreto portuguesa mais antiga é o convento de Santiago do Cacém (1505), outra houve que foi praticamente sua contemporânea, uma fundação particular, depois tornada pública e cedida à paróquia, a já atrás mencionada igreja da Lombada do Loreto, na Ilha da Madeira (Fig. 1). Actualmente erigida também ela em paróquia (no ano de 1961), a sua origem é muito mais antiga, pois, de facto, foi fundada cerca de 1510 por D. Joana de Eça, mulher de Pedro Gonçalves da Câmara, um dos filhos do capitão donatário João Gon-

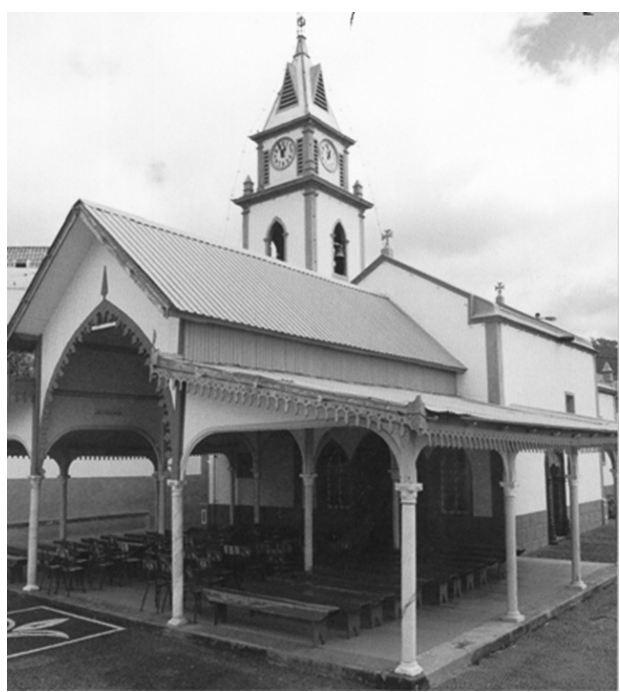

Fig. 1 Capela do Loreto, no concelho da Calheta (Cardoso e Baptista 2001: 89). çalves da Câmara, isto junto de umas fazendas e casas nobres que aqui tinha, próximo do lugar do Arco da Calheta (Sousa 1745: 709710). Esta capela tornou-se depois o centro de uma das mais antigas romagens da Ilha da Madeira, celebrador todos os anos nos dias 7 e 8 de Setembro (Vieira 2000: 285; Almeida e Belo X, 2008: 235). 
Passados 25 anos, um frade franciscano natural de Bragança, Fr. Manuel Curvo, saindo da clausura do seu convento, foi a Roma, onde alcançou do Papa Paulo III (1534-1549) uma bula (no ano de 1536) para fundar uma casa de regra mais estrita, e visitando "a Casa \& Santuário de Nossa Senhora do Loreto \& tanto se affeyçoou aquella milagrosa Imagem, que recolhendo-se a Portugal $\&$ indo direyto à Cidade de Bragança, de donde parece que era natural, alli procurou levantar \& dedicar à Senhora huma Ermida, em que em vida retirada solitaria \& contemplativa servi-se a Nosso Senhor. Para isto se ofereceo o Licenciado Manoel Gomes Correa, dando-lhe hum sitio muyto accommodado ao seu intento. Neste levantou huma Ermida (em 1545) que dedicou à Virgem Nossa Senhora com o titulo do Loreto, pela grande devoção que lhe tinha, depois que visitou aquella sua devota Casa \& Camera Angelical da Provincia da Marca ou de Recanate. Nesta Ermida collocou o devoto Padre huma imagem da Senhora que dizem os moradores daquella Cidade a trouxera de Italia, ou a cabeça $\&$ as mãos porque hé de roca $\&$ de vestidos $\&$ no raro de sua grande fermosura se entende bem que só lá podia ter feyta, por haver naquelas partes insignes escultores. E está tão bella \& a encarnação tão fresca, que parece ser obrada de poucos dias. Tem em seus braços hum lindissimo Menino, que também trouxe de Itália o mesmo Padre \& quiz que em tudo se representasse o seu Original" (Santa Maria 1716: 553-559).

Arruinada a casa de Bragança, foi depois reparada já nos fins do século XVII pelo Pe. João de Prada, Abade de Monforte do Rio Livre, junto a Chaves, terras onde este padre haveria de fundar, como veremos, outras duas ermidas da mesma invocação.

Houve nesta casa do Loreto de Bragança duas confrarias, uma de seculares e outra de eclesiásticos, mas de pouca duração. Por voto antigo dos vereadores, a Câmara ia todos os anos no dia de Santo Amaro em visita a esta igreja, mandan- 
do celebrar uma missa cantada. Teve um recolhimento de oblatas do Menino Jesus, vulgo Beatas, que vindo de Mofreita, aqui se estabeleceram em 20 de Maio de 1819 (Ruivo, 1995: 357-358).

Pelos mesmos anos em que se edificou a casa do Loreto de Bragança, também se edificou a do Loreto em Coimbra, por mercê de outro peregrino que passou pela casa italiana, o Bispo de Coimbra, que em 16 de Março 1548, segundo documento do arquivo do Cabido, concedeu licença a Fr. Manuel (Teles) para fundar uma ermida de Nossa Senhora do Loreto num olival de Leonor Cabral, dona viúva, moradora em Coimbra (Castro, 1867: 257). Este Bispo de Coimbra era D. João Soares (1545-1572), religioso da Ordem dos Eremitas de Santo Agostinho (a mesma ordem do Mosteiro de Santa Cruz), "varaō de grandes letras, \& virtude (que) por ser de tantas qualidades (...) foi deste Reyno mandado ao Concilio de Trento; de caminho visitou a casa Santa de Loreto, \& com a devaçaó do lugar determinou vir edificar no seu Bispado outra Igreja da mesma invocação" (Brandão, 1650: 201-202).

Além destas três capelas públicas, outras dez são mencionadas nas memórias paroquiais do século XVIII, sendo conhecidas as origens daquelas que foram fundadas nos antigos limites do Arcebispado de Braga, nomeadamente, em Fradelos (Vila Nova de Famalicão) (1616/ 1640) ${ }^{15}$; no Lugar de Cabanas, Sabadim (Arcos de Valdevez) edificada por Francisco de Caldas e Araújo, abade, natural desta freguesia $(1703 / 1719)^{16}$; e no Lugar de Sabroso de Aguiar (Vila Pouca de Aguiar), fundada pelo Pe. Belchior Machado (1737

${ }^{15}$ Universidade do Minho - Arquivo Distrital de Braga, Mitra Arquiepiscopal de Braga, Registo Geral, liv. 12, fls. 199-201; liv. 30, fls. 8-11 (doravante PT/UM-ADB/ $\mathrm{DIO} / \mathrm{MAB}$ seguido por $\mathrm{n}$. registo livro/ folha)

${ }^{16} \mathrm{PT} / \mathrm{UM}-\mathrm{ADB} / \mathrm{DIO} / \mathrm{MAB} / 001 / 0041 / 010789 ; \mathrm{PT} / \mathrm{UM}-\mathrm{ADB} / \mathrm{DIO} /$ MAB/001/0044/011025; PT/UM-ADB/DIO/MAB/001/0153/035099. 
/ 1751$)^{17}$, a qual teve uma confraria da mesma invocação, erigida pelos moradores do lugar em $1740^{18}$.

Esta última capela foi descrita por Pinho Leal em 1882 como uma ermida "muito interessante (...) perfeitamente quadrada, tendo somente portas lateraes (...) toda de abóbada de cantaria, com um elegante zimbório, sendo as suas paredes interiores, bem como o tecto, revestidas com quadros, representando varios factos da vida da S. S. Virgem. As paredes da todos os quatro lados, estão coroadas com as estátuas dos 12 apóstolos; e em cada um dos ângulos, uma de N. Senhora, symbolisando a Turris Davidica. Tem um só altar, onde se admira a belíssima imagem da Senhora do Loreto. Dos lados, tinha em nichos, as imagens dos apóstolos e dos evangelistas; mas hoje apenas restam alguns, e mutilados. Não me consta que haja era Portugal, outro templo de egual estylo architectonico. Apezar de todas estas maravilhas, este templo está em completo e reprehensivel abandono!" (Pinho Leal 1882: 301-306). Diz o mesmo autor que "é tradição constante na freguezia, que um individuo natural de Sabrôso, chamado Antonio Machado (sic), fora para a Itália, d'onde regressou a esta freguezia com ordens de presbytero, e que, em cumprimento de um voto, mandou construir esta ermida, onde foi sepultado, em uma campa raza”. Foi acabada em 1751, pelo arquitecto Diogo Lopes, espanhol; o que consta de uma inscrição que estava na parede interior.

No Dicionário Geográfico do Pe. Luís Cardoso (1747/1751) são também mencionadas as capelas públicas de Alcafozes (Idanha-a-Nova) (Cardoso 1747: 150) e Babe (Bragança) (Cardoso 1751: 2). Nas memórias paroquiais de 1758 são mencionadas as de Sanfins (Valença) (Capela 2005: 374), Cristelos (Lousada) (Fig. 2) (Capela 2009: 188), Vila Nova de Oliveirinha (Tábua) (Capela 2011: 811) e Cernache do Bonjardim (Sertã) (Silva 2013: 286). Havia ainda

\footnotetext{
${ }_{17}$ PT/UM-ADB/DIO/MAB/001/0059/012636.

${ }^{18} \mathrm{PT} / \mathrm{UM}-\mathrm{ADB} / \mathrm{DIO} / \mathrm{MAB} / 001 / 0089 / 018848$.
} 


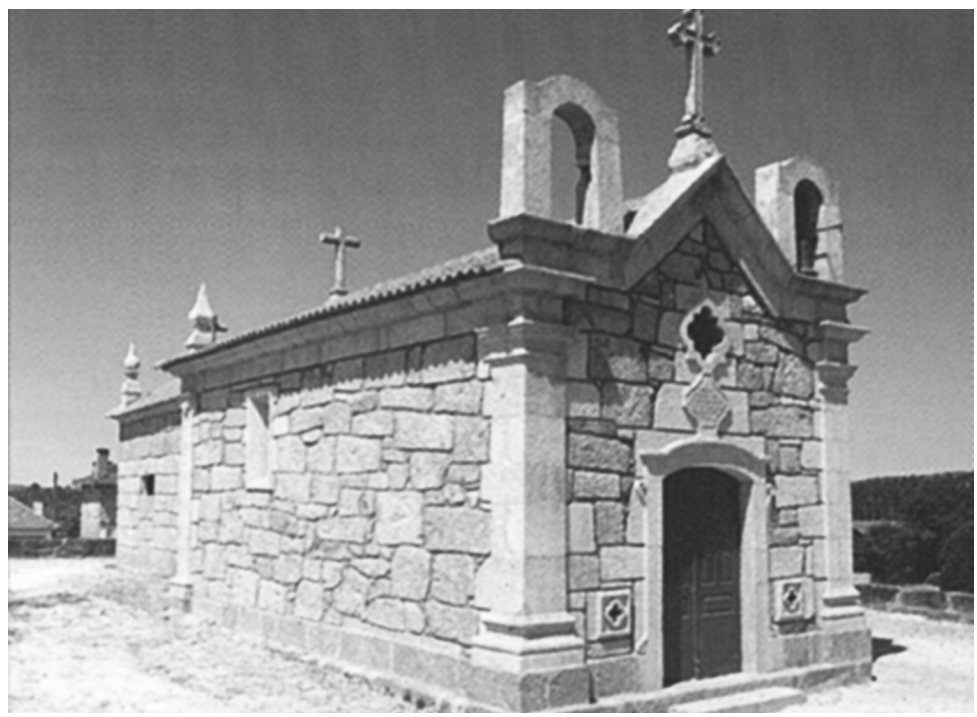

Fig. 2 Capela no Alto da Senhora do Loreto, em Cristelos (Lousada) (Gomes 1996: 90).

uma em Monção, não mencionada nas memórias paroquiais, a qual foi demolida em $1924^{19}$.

Oratórios e Capelas particulares (24)

Neste levantamento feito para os lugares de culto de Nossa Senhora do Loreto em Portugal, nomeadamente igrejas paroquiais, conventos, capelas públicas e capelas particulares, que necessariamente se revelará incompleto, em especial quanto a estas últimas, para as quais não existem levantamentos mais abrangentes, não deixa ainda assim de ser significativo que os oratórios ou capelas particulares representem mais de metade das 42 casas identificadas.

Das capelas particulares, além da já atrás mencionada capela do Loreto da Ilha da Madeira - inicialmente capela pri-

${ }^{19}$ Arquivo Contemporâneo do Ministério das Finanças, Comissão Jurisdicional dos Bens Cultuais, Administração dos Bens Cultuais, Cx. 180, Proc. 9112, fl 226. 
vada, depois pública e hoje igreja paroquial - as mais antigas com o título de Nossa Senhora do Loreto foram as capelas do Morgado dos Biscoitos na Ilha Terceira (Açores) e a do Morgado do Loreto em Tavira, ambas já referidas no século XVI.

A ermida terceirense (Fig. 3) foi edificada por Pedro Anes do Canto, Provedor das Armadas e Naus da Índia em todas as ilhas dos Açores (1532). A data da sua construção é desconhecida, possivelmente data dos anos de 1540, visto que ele faleceu em 1556 (Lucas 1976: 283286), e ficava originalmente "junto das grandes, \& ricas casas em que elle viveo, boa meya legoa do mar, \& com Missa na Ermida, que he a cabeça do morgado" (Cordeyro 1717: 254).

Quanto à ermida algarvia, desconhece-se o seu fundador,

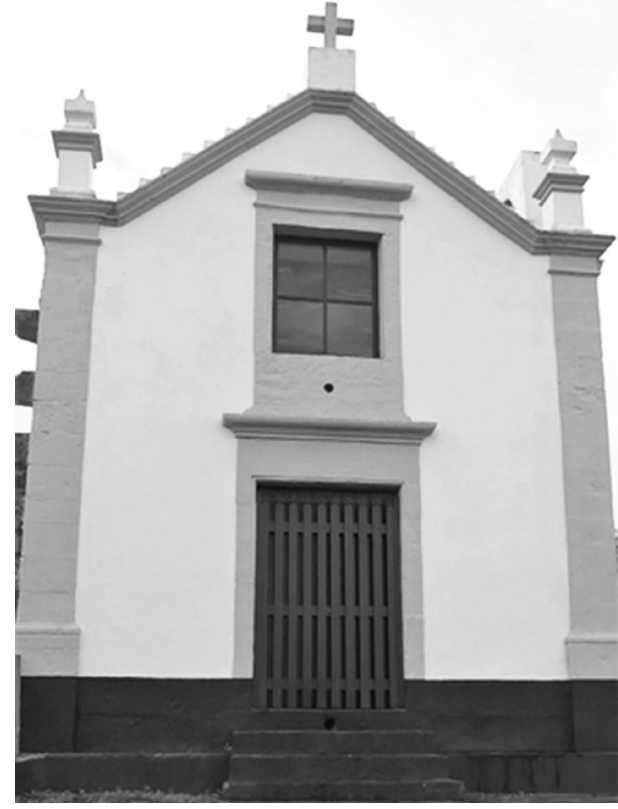

Fig. 3 Ermida de Nossa Senhora do Loreto, freguesia dos Biscoitos (fot. Carlos Luís M C. da Cruz, 2017). mas esta está documentada na passagem por Tavira de El Rei D. Sebastião no ano de 1573, dia 1 de Fevereiro, em que "ouviu El-Rei missa na cidade de Tavira, numa ermida da advocação de Nossa Senhora do Loreto, que está nas próprias casas em que el-Rei pousou" ${ }^{20}$. Este solar e capela (Fig. 4) pertenciam no século XVIII a João de Mendonça Corte

${ }^{20}$ Biblioteca Nacional de Portugal (BNP), Fundo Geral, Cód. 109, fl. 47v, apud Serrão, 1987: 272. 
Real, Governador de Tavira, que em 1727 ali fundou uma capela de missas e mais encargos pios, que ficaram anexos em morgado ao hospital conhecido no século XIX como Hospital de S. José (Lopes 1841: 360). Esta ermida (já derrubada) ficava onde actualmente está o coreto do Jardim, inaugurado em 1890, e a imagem de Nossa Senhora está actualmente na Igreja de São Francisco ${ }^{21}$.

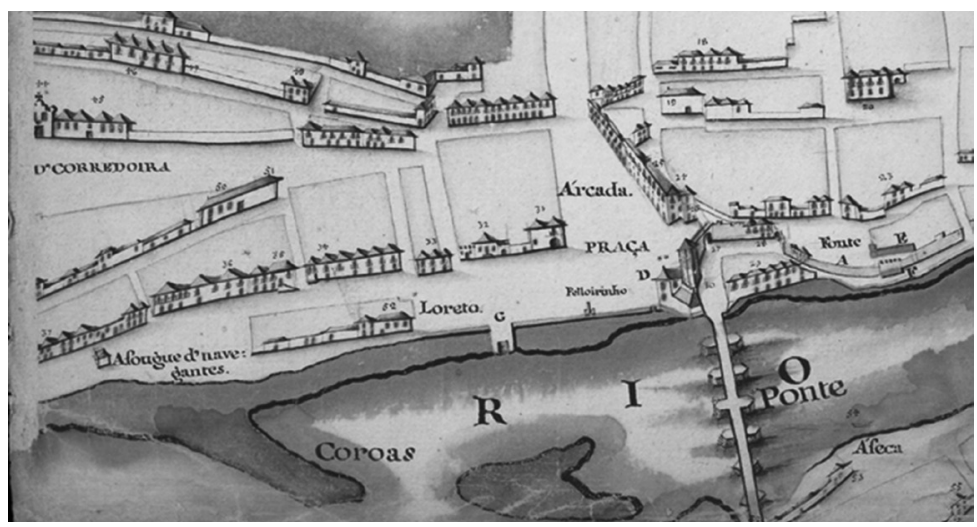

Fig. 4 Excerto de Planta de Tavira no século XVIII: Casa do Morgado do Loreto, aut. José de Sande Vasconcelos ${ }^{22}$.

No século XVII temos a notícia de fundação de quatro capelas particulares dedicadas a Nossa Senhora do Loreto, na:

- Casa de Torgueda (Vila Real), instituída por Francisco Ferreira Velho, da vila do Lordelo, cabeça de vínculo e morgado em 1644 (Pegas 1687: 277; Sousa; Gonçalves 1987: 534; Capela 2006: 175, 232);

- Casa ou Solar do Silveiras, em Guiães (Vila Real), fundada com o título de São Pedro em 1671, pelos ascendentes de Francisco José Taveira Pimentel, seu proprietário em 1758, vindo depois a ter a invocação do Loreto $^{23}$;

\footnotetext{
${ }^{21} \mathrm{http} / /$ www.viva-tavira.com/Igrejas/igrejas_files/010sFrancisco.htm (2.6.2018).

${ }_{22}$ Biblioteca Nacional do Brasil (BNB), Cartografia, Arc.025,09,007.

${ }^{23} \mathrm{http} / /$ www.monumentos.gov.pt/Site/APP_PagesUser/SIPA.aspx?id=5775
} (2.6.2018). 
- Casa da Quinta das Amendoeiras, aos Olivais (Lisboa), fundada em 1675 pelo Dr. João Freire de Melo, Tesoureiro Mór ${ }^{24}$;

- Casa da Quinta da Cartacheira, em Carcavelos (Cascais), fundada em 1694 pelo mercador genovês Cesar Ghersi, que foi um dos principais benfeitores da Igreja de Nossa Senhora do Loreto dos Italianos em Lisboa (Mendes 2016: 133);

- Solar do Loreto, na Fajã de Baixo (Ponta Delgada), mandada edificar por Lourenço de Frias Coutinho, Capitão do Donatário da Ilha de Santa Maria, que por escritura de 15 de Julho de 1699 fez património a esta ermida (Canto 2000: 179).

No século XVIII são vários os registos de fundação e memória de ermidas particulares dedicadas ao culto de Nossa Senhora do Loreto, desde logo duas ermidas na região de Chaves edificadas pela devoção do Pe. João de Prada, Abade de Monforte do Rio Livre, que já havia ordenado várias obras na Casa do Loreto de Bragança, pela qual tinha grande devoção, por ser sua terra natal. De facto, em 1696, este clérigo fundou no Toural de Chaves um morgadio com uma capela anexa dedicada a Nossa Senhora do Loreto, onde depositou as relíquias de São Bonifácio Mártir, que deram à mesma o nome do Santuário da Santa Cabeça. A ermida, em que a imagem da padroeira se acha colocada no retábulo mor em estilo nacional, foi aberta ao culto em $1703^{25}$. Além da capela de Chaves, João de Prada mandou também construir outra capela da mesma invocação em Monforte de Rio Livre, onde era abade, no lugar de Águas Frias (Pinho Leal 1880: 142).

No século XVIII registam-se nos arquivos diocesanos de Braga algumas licenças para a construção de capelas com esta invocação em casas particulares, na:

- Quinta de Cortamil, em Venade (Caminha), fundada entre 1704 e 1717 por Bartolomeu Pereira da Cunha, da

${ }^{24}$ ANTT, Câmara Eclesiástica de Lisboa, mç. 1809, n. ${ }^{\circ} 156$.

${ }^{25} \mathrm{PT} / \mathrm{UM}-\mathrm{ADB} / \mathrm{DIO} / \mathrm{MAB} / 001 / 0041 / 010792$. 
vila de Caminha, que tinha especial afeição à N. ${ }^{a} S r{ }^{a}$ do Loreto $^{26}$;

- Casa de Santa Cruz (Ponte de Lima) erigida entre 1710 e 1712 por Vitório de Araújo e Almeida ${ }^{27}$;

- Quinta de Vila Boa, em Crujães, Várzea (Barcelos) erigida pelo Padre Doutor Manuel Pereira de Araújo, Cónego Prebendado da Sé de Braga, em 173128;

- Casa do Arco da Ferraria, no Campo do Tabuado (Vila Real), fundada por Francisco Pereira Pinto, Mestre de Campo do Terço de Auxiliares de Vila Real, Governador da Praça de Chaves com o posto de Coronel de Cavalaria (Teixeira 1951: 240), fidalgo e morador em Vila Real, em 175329; e

- Casa no sítio de Pegóes (Montijo), fundada em 1765 por um Martinho João ${ }^{30}$;

- Casa da Senhora do Loreto (Sabrosa), edificada por Francisco Xavier de Barros de Mesquita, tutor de sua sobrinha D. Maria Comba Botelho e Vasconcelos, em $1787^{31}$.

Além destas capelas particulares, de que se conhece a fundação, outras houve, mencionadas sobretudo nas memórias paroquiais, mas não só, que terão sua origem nos séculos XVII e XVIII, tais como as da:

- Casa de Carcaveira, em Sá (Ponte de Lima), de João de Barros Barbosa (1758) (Capela, 2005, 365);

- Quinta da Lagoa, em Prados de Baixo, Vila da Rua (Moimenta da Beira) (Fig. 5) (1758) (Encarnação 1877: 159; Capela 2010: 867);

- Casa de Aldeias (Armamar) (1758) (Encarnação 1877: 143);

${ }^{26} \mathrm{PT} / \mathrm{UM}-\mathrm{ADB} / \mathrm{DIO} / \mathrm{MAB} / 001 / 0041 / 010796$;

PT/UM-ADB/DIO/MAB/001/0043/010966; Moreira, 2006: 49, 56-57.

${ }^{27}$ PT/UM-ADB/DIO/MAB/001/0042/010907; Moreira, 2006: 47.

${ }^{28} \mathrm{PT} / \mathrm{UM}-\mathrm{ADB} / \mathrm{DIO} / \mathrm{MAB} / 001 / 0117 / 024660$.

${ }^{29} \mathrm{PT} / \mathrm{UM}-\mathrm{ADB} / \mathrm{DIO} / \mathrm{MAB} / 001 / 0151 / 033679$.

${ }^{30}$ ANTT, Câmara Eclesiástica de Lisboa, mç. 1809, n. ${ }^{\circ} 252$.

${ }^{31} \mathrm{PT} / \mathrm{UM}-\mathrm{ADB} / \mathrm{DIO} / \mathrm{MAB} / 001 / 0219 / 050481$. 
- Casa de Frechão (Trancoso), fora do lugar, administrada por Manuel Ferreira, da freguesia (1758) (Capela 2013: 702);

- Casa do Pe. António de Figueiredo, em Oliveira do Conde (Carrega do Sal) (1758) (Capela 2010: 857);

- Casas do Taipal (Montemor-o-Velho), dedicada a Senhora do Loreto e Cristo Crucificado (1758) (Capela 2011: 806);

- Casa de Arcozelo de Além, em Novelas (Baião), de Manuel Francisco Leal da Veiga (1758) (Capela 2009: 200);

- Casa de Diniz, em Santa Cristina do Couto (Santo Tirso), de António Correia da Silva (1758) (Capela 2009: 205); e

- Casa de Aveloso (Meda) de Nicolau de Tovar de que é senhor da antiga casa D. José António de Lucena Noronha e Faro moço fidalgo que foi D. Prior da colegiada de Cedofeita, no Porto (1877) (Encarnação 1877: 165).

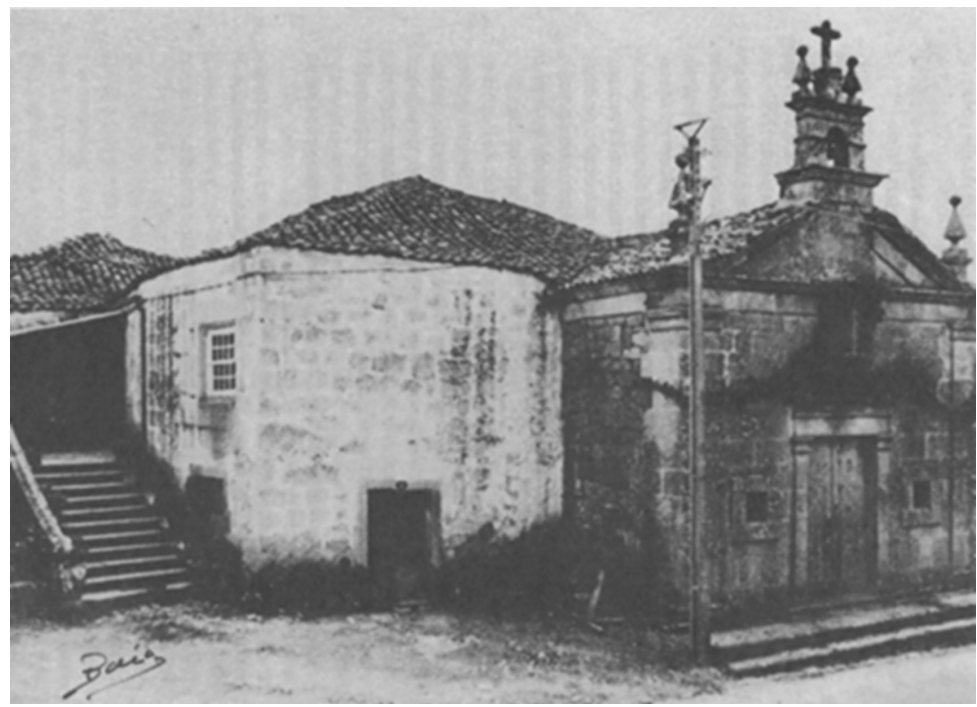

Fig. 5 Capela e Quinta da Lagoa, Prado de Baixo, Vila da Rua (Moimenta da Beira) (Guia 2001: 247). 


\section{NOTAS FINAIS}

Além das casas dedicadas a Nossa Senhora do Loreto, o seu culto esteve ainda presente em vários altares, através de imagens e das respectivas irmandades. Neste âmbito identificámos 10 referências entre os séculos XVI e XVIII, sobretudo no Norte de Portugal, a que constituem excepção duas imagens no Alentejo, uma na Igreja da Misericórdia de Elvas, ali colocada em 1712 por António Luís Godinho (Santa Maria 1721: 592-594) e outra na Misericórdia de Vila Viçosa, em altar da mesma invocação com retábulo datado de 1727 (Almeida e Belo VIII 2008: 204); uma segunda confraria em Lisboa, na Capela de S. Mateus da Casa do Marquês de Cascais em $1739^{32}$; e uma imagem na igreja matriz da Ribeira Grande, nos Açores, consagrada pelo Bispo de Angra, D. Pedro de Castilho, em 1581 (Cardoso 1657: 107), imagem que parece ter sido a invocação de uma primitiva ermida da Ribeira Grande, do tempo de D. Manuel (Canto 2000: 180).

Quanto às restantes sete imagens, encontramo-las dispersas por várias casas de culto, nomeadamente em altares - uma na Igreja de São Pedro de Vila Real ali colocada por António Alvares Nogueira em $1729^{33}$ e outra na Igreja de Jovim (Gondomar) (Capela 2009: 247) - e em capelas, nomeadamente na:

- Sé de Braga, capela fundada e dotada pelo Reverendo Cónego Diogo de Castro no ano de 1706, onde "colocou hum quadro copiado pela imagem da mesma Senhora do Loreto, cujas tintas foraó pesada pela tigelinha do Menino Deos, que se conserva em Itália no Santuário da Cidade do

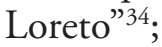

\footnotetext{
${ }^{32}$ ANTT, Câmara Eclesiástica de Lisboa, mç. 1807, s/n. ${ }^{\circ}$.

${ }_{33}$ PT/UM-ADB/DIO/MAB/001/0048/011251.

${ }^{34}$ ANTT, Memórias paroquiais, vol. 7, no 57, p. 1113 a 1122; Capela, 2003: 174
} e 215 . 
- Convento de São Domingos do Porto, fundada por Catarina Fernandes Baião em 1548

- Convento de São Francisco de Vila Real, mandada executar por António Álvares Nogueira, em troca de uma sepultura no supedâneo (Figueiredo 2009: 265);

- Igreja paroquial de Monserrate em Viana do Castelo, fundada em 1611 com a invocação de São Bento e Santa Catarina por Bento Martins Viana e sua mulher Catarina Ramos, a qual depois foi dedicada à Virgem do Loreto em 1748 (Cardona 2012: 273); e

- Igreja paroquial de Durrães (Barcelos) $(1758)^{36}$.

De um modo geral, podemos afirmar que, para lá das próprias casas religiosas (conventos e recolhimentos), notase que várias casas lauretanas portuguesas têm associados fundadores ligados à espiritualidade franciscana, realidade muito provavelmente relacionada com a relativa proximidade de Assis e Loreto, no contexto da cartografia religiosa italiana, mas também devido à acção missionária franciscana que recorria muitas vezes às ladainhas da Virgem do Loreto, uma rara manifestação pós tridentina, as quais foram aprovadas pelo Papa Sixto V, no ano de 1587, e que começaram a ser difundidas a partir desse "santuário, onde é cantada solenemente em todos os Sábados" (Barros 1927: 270; Cardoso 2014: 175).

Das actuais dioceses do país, só não registamos casas do Loreto em duas delas - Leiria e Aveiro - ainda que, nesta última, se deva destacar o culto que se prestava à Senhora do Loreto no Convento da Madre de Deus de Sá, fundado em 1644 por religiosas vindas do Convento do Loreto de Almeida (Santa Maria 1711: 219). Mas ainda que existam casas do Loreto em quase todas as dioceses ou regióes de Portugal, o

${ }^{35}$ BNP, Codice 8423, Instituição da Capela de Nossa Senhora do Loreto; Pinho, 2000: 53, 154 .

${ }^{36}$ ANTT, Memórias paroquiais, vol. 13, no 32, p. 191 a 196; Capela, 2003: 212. 
seu culto está distribuído de forma desigual pelo país, sendo muito mais frequente no Norte que no Sul, com especial destaque para as dioceses Vila Real e Viana do Castelo.

\section{Conclusāo}

O culto de Nossa Senhora do Loreto estabelece-se em Portugal logo no início do século XVI associado à devoção que o santuário do Loreto teve, sobretudo para aqueles que demandavam as terras italianas. Tratava-se em particular de bispos e religiosos ligados à espiritualidade franciscana, que, ao regressarem a Portugal, traziam relíquias das Santa Casa do Loreto (terra, ladrilhos, etc.), ou mesmo estatuária e pintura feita à imagem da Nossa Senhora que estava na Casa do Loreto de Itália.

Foi assim uma devoção com manifestações em quase todo o país, mas que, curiosamente, acabou por não ter muita expressão entre os lugares de culto fundados por italianos em Portugal, circunscrevendo-se nestes a uma igreja e uma capela particular.

\section{BibLIOGRAFIA}

Almeida, Álvaro Duarte de; BELO, Duarte (2008), Portugal património, Vol. VIII: Portalegre e Évora; Vol. X: Açores e Madeira, [Lisboa], Círculo de Leitores.

Barros, João Crisóstomo Freitas, trad. (1927), Missal dos fiéis: Devocionário e Sacramentário, Lisboa, [s.n.].

Belém, Fr. Jerónimo de (1753), Chronica serafica de Santa Provincia dos Algarves da Regular, Tomo II, Lisboa, Mosteiro de São Vicente de Fora.

Boissellier, Stéphane (2012), La construction administrative d'un royaume, Lisboa, CHER-UCP.

Brandão, Fr. Francisco (1650), Monarchia Lusitana: 5. a Parte que contem a historia dos primeiros 23. annos del Rey D. Dinis, Lisboa, Of. Paulo Craesbeeck.

Canto, Ernesto do (2000), "Notícias sobre as Igrejas, Ermidas e Altares da Ilha de São Miguel”, Insulana, LVI, pp. 113-250.

Capela, José Viriato (2013), As Freguesias do Distrito da Guarda nas Memórias Paroquiais de 1758. 
- (2011), As Freguesias dos Distritos de Aveiro e Coimbra nas Memórias Paroquiais de 1758.

- (2010), As Freguesias do Distrito de Viseu nas Memórias Paroquiais de 1758.

- (2009), As Freguesias do Distrito do Porto nas Memórias Paroquiais de 1758.

- (2006), As Freguesias do Distrito de Vila Real nas Memórias Paroquiais de 1758.

- (2005), As freguesias do Distrito de Viana do Castelo nas Memórias Paroquiais de 1758.

- (2003), As Freguesias do Distrito de Braga nas Memórias Paroquiais de 1758.

Cardona, Paula Cristina Machado (2012), Confrarias em Viana do Castelo: A encomenda artística dos séculos XVI a XIX, Ediçōes Afrontamento, Lda.

Cardoso, Jorge (1657), Agiologio Lusitano, Tom. II, Lisboa, Of. Henrique Valente d'Oliveira.

Cardoso, Luís (1747-1751), Diccionario geografico, ou noticia historica de todas as cidades, villas, lugares, e aldeas, rios, ribeiras, e serras dos Reynos de Portugal, e Algarve (...), Tom. I, 1747; Tom. II. 1751, Lisboa, na Regia Officina Sylviana, e da Academia Real. Cardoso, Pedro Alexandre Almeida de Vasconcelos Gomes (2014), Estudo da Arte da Talha das Capelas particulares dos Arciprestados de Lamego e Tarouca. Tese de Doutoramento em Estudos de Património, orient. Gonçalo de Vasconcelos e Sousa, I, UCP. Cardoso, Zita; Baptista, John (2001), Igrejas e Capelas, Festas e Arraiais, Madeira e Porto Santo: A riqueza do património desta Regiāo, 2. ${ }^{\mathrm{a}}$ ed., Funchal, Aguim Madeira.

Castro, Augusto Mendes Simões de (1867), Guia historico do viajante em Coimbra e arredores, Coimbra, Imprensa da Universidade.

Castro, Abade de (1848), "Miguel Angelo Buonaroti e Manoel Campello", Revista Universal Lisbonense, Tomo VII: Anno de 1847-1848, Lisboa, Imprensa da Gazeta dos Tribunaes, pp. 498-499.

Castro, Pe. José de (1947), Bragança e Miranda (Bispado), II, Porto, Tipografia Porto Médico.

Conceição, Fr. Apolinário da (1740), Claustro Franciscano, erecto no dominio da Coroa Portugueza (...), Lisboa Occidental, Of. Antonio Isidoro da Fonseca.

Cordeyro, António (1717), Historia insulana das ilhas a Portugal sugeytas no oceano occidental, Lisboa Occidental, Of. Antonio Pedrozo Galram.

Encarnação, Joaquim da (1877), Historia ecclesiastica de cidade e bispado de Lamego. Typ. do Jornal de Porto.

Figueiredo, Ana Paula Valente (2009), Os Conventos franciscanos da Real Província da Conceição. Análise Histórica, Tipológica, Artística e Iconográfica, Tese de doutoramento, História (Arte, Património e Restauro), orient. Vítor Serrão, FLUL.

Gomes, Paulino, coord. (1996), Lousada: Terra prendada, 2. ${ }^{a}$ ed., Paços de Ferreira, Anegia Editores.

Guia, A. Bento da (2001), As vinte freguesias de Moimenta da Beira, Câmara Municipal, $3 .^{\mathrm{a}}$ ed.

Infante, Cónego António Franco (1985), Culto Marial na Diocese de Portalegre-Castelo Branco, s.l., Editorial SPES. 
Leitão, João, Nossa Senhora do Loreto: Padroeira Universal da Aviação, Alcafozes, Associação Portuguesa de Tripulantes de Cabine, 5-8-2014, <https://ecitydoc.com/download/livro-de-alcafozes-ediao-aptca-download-aqui_pdf>

Lopes, João Baptista da Silva (1841), Corografia: ou, Memoria economica, estadistica, e topografica do Reino do Algarve, Lisboa, Typ. da Academia.

Lucas, Pe. Alfredo (1976), As Ermidas da Itha Terceira, Angra do Heroísmo, (reed. 2014), [S.1.], BLU.

Mendes, Rui Manuel Mesquita (2016), "Câmara Eclesiástica de Lisboa: Contributos para o estudo da presença dos italianos e famílias de origem italiana na região de Lisboa (séculos XVI, XVII e XVIII)", Nunziatella Alessandrini, Susana Bastos Mateus, Mariagrazia Russo e Gaetano Sabatini (org.), Scrigni della Memoria: Arquivos e Fundos documentais para o estudo das relações luso-italianas, Cátedra de Estudos Sefarditas "Alberto Benveniste”, pp. 115-150.

Moreira, Manuel António Fernandes (2006), O Barroco no Alto Minho, Viana do Castelo, CER.

Pegas, Manuel Álvares (1687), Tractatus de exclusione, inclusione, succesione \& erectione maioratus, Tom. II, Lisboa, Of. Antonio Leite Pereira.

Pinho Leal, Augusto Soares de Azevedo Barbosa de (1880), "Senhora do Loreto", Portugal antigo e moderno : diccionario geographico, IX, Lisboa, Livraria Editora Tavares Cardoso \& Irmão, pp. 140-142.

Pinho Leal, Augusto Soares de Azevedo Barbosa de (1882), "Verea de Bornes", Portugal antigo e moderno: diccionario geographico, X, Lisboa, Livraria Editora Tavares Cardoso \& Irmão, pp. 301-306.

Pinho, Isabel Maria Ribeiro Tavares de (2000), O Mosteiro de São Bento de Avé Maria do Porto, 1518/1899. Uma Arquitectura no século XVIII, I, Porto, UP.

Ruivo, Luís José Afonso (1995), Cidade de Bragança e freguesia da Sé, Bragança, Nordeste.

Santa Maria, Fr. Agostinho de (1707-1723), Santuario Mariano, e historia des image s milagrosas de Nossa Senhora, Lisboa, Antonio Pedrozo Galraõ, Tom. III, 1711; Tom. V, 1716; Tom. VI, 1718; Tom. VII, 1721.

Santarém, Visconde de (1845), Quadro elementar das Relaçôes Politicas e Diplomaticas de Portugal (...), Tom. V, Lisboa, Typ. da Academia Real das Sciencias.

Serrão, Joaquim Veríssimo (1987), Itinerários de el-rei D. Sebastião (1568-1578), 2a ed., Lisboa, Academia Portuguesa de História.

Silva, Joaquim Candeias da (2013), Cernache do Bonjardim: Subsídios históricos, Junta de Freguesia.

Sousa, António Caetano de (1745), Historia genealogica da casa real Portugueza, XI, Lisboa Occidental, na regia officina Sylviana, e da Academia Real, pp. 709-710.

Sousa, Fernando de; et Gonçalves, Silva (1987), Memórias de Vila Real, Vol. II, Vila Real, Arquivo Distrital, Câmara Municipal. 
Tavares, António Henriques (1989), Pessegueiro do Vouga: Das Origens à actualidade, Aveiro, Estante Editora.

Teixeira, Júlio A. (1951), Fidalgos e morgados de Vila Real e seu termo, J.A. Telles da Sylva.

Vieira, Alberto (2000), "FUNCHAL, diocese do", in Dicionário da História Religiosa de Portugal, dir. Carlos Moreira Azevedo, II: C-I, CEHR-UCP / Círculo de Leitores, pp. 281-288.

Vieira, João Martins (2017), Invocaçôes a Nossa Senhora na cidade de Lisboa, Livros Horizonte. 